
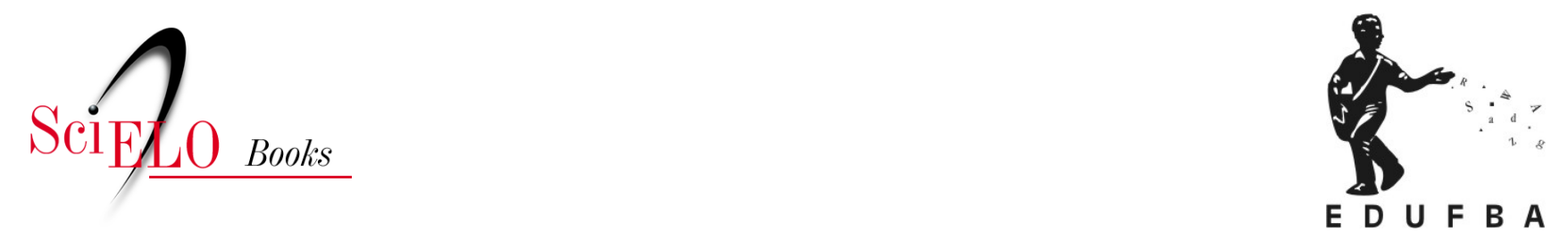

\title{
De quando a publicidade se encontra com as artes visuais a imagem publicitária e a construção da interpretação
}

\author{
Renata Voss Chagas
}

\section{SciELO Books / SciELO Livros / SciELO Libros}

CHAGAS, R.V. De quando a publicidade se encontra com as artes visuais: a imagem publicitária e a construção da interpretação. In: HERNÁNDEZ, M.H.O., and LINS, E.Á., eds. Iconografia: pesquisa e aplicação em estudos de Artes Visuais, Arquitetura e Design [online]. Salvador: EDUFBA, 2016, pp. 138-149. ISBN: 978-85-232-1861-4. https://doi.org/10.7476/9788523218614.0009.

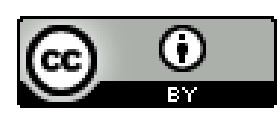

All the contents of this work, except where otherwise noted, is licensed under a Creative Commons Attribution $\underline{4.0 \text { International license. }}$

Todo o conteúdo deste trabalho, exceto quando houver ressalva, é publicado sob a licença $\underline{\text { Creative Commons }}$ Atribição 4.0. 


\section{De quando a}

publicidade se

encontra com as

artes visuais: a

imagem publicitária

e a construção da

interpretação

Renata Voss Chagas 


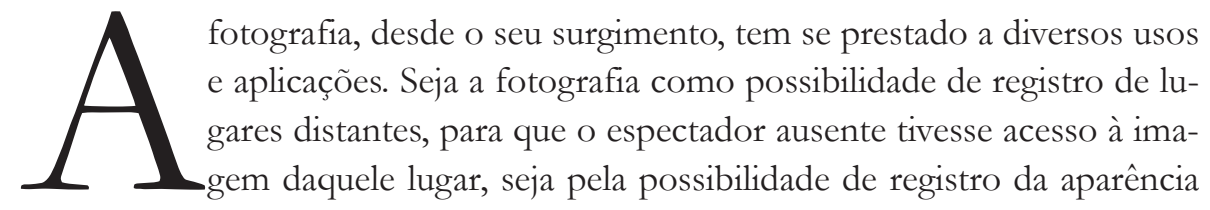
das pessoas, através de retratos que podiam denunciar e identificar presidiários (FABRIS, 1998), ou mesmo tendo as aplicações no jornalismo, na arte ou na publicidade, havendo, em cada aplicação, as suas características de linguagem e as suas particularidades, no que diz respeito ao modo de construção da imagem.

Enquanto na arte temos um território mais livre para criação, em que o que norteia a produção é a poética do artista, no jornalismo tem-se uma ampla tradição que vai relacionar essa construção como representação de uma realidade. Já na publicidade, há maior liberdade para a construção da cena a ser fotografada, devendo, neste tipo de aplicação, existir muito mais um apelo de compra ou mesmo uma imagem-conceito que será vinculada à imagem que temos de uma determinada marca.

Devemos considerar a fotografia não como uma imagem inocente, tendo em vista que toda fotografia será um recorte de um tema selecionado pelo fotógrafo, registrado mediante uma tecnologia, que seria representada pelos equipamentos 
utilizados para captura da imagem. Ao fazê-lo, o fotógrafo age como um filtro cultural: inscreve naquela imagem as suas crenças, sua ideologia, através de sua bagagem cultural e sua sensibilidade. Toda fotografia será um recorte de tempo que seria a data, o momento, a época do registro - e de espaço, sendo este, geográfico, o local da captura da fotografia. (KOSSOY, 2001) Conforme Kossoy (2001, p. 50), "Toda fotografia é um testemunho segundo um filtro cultural, ao mesmo tempo que é uma criação a partir de um visível fotográfico". Ou seja, distante dos discursos que prezam pela gênese da fotografia como baseada no dispositivo e que, por isso, essa imagem seria tida como neutra, as teorizações sobre esse tipo de imagem já muito avançaram ao considerar o fotógrafo como autor e agente, e os meios de circulação e distribuição, também, como determinantes nos sentidos que uma imagem pode adquirir.

Pretendemos, aqui, abordar a questão da utilização da fotografia pela publicidade e de que modo, muitas vezes, ela vai se relacionar com as artes visuais: seja ao incorporar gêneros já estabelecidos pelas artes ou mesmo ao realizar composições construídas que remetem às imagens do decorrer da história da arte, sendo necessário um vasto conhecimento desta iconografia tanto para a construção da imagem como para a sua interpretação. Para tanto, realizaremos um breve histórico do uso da imagem na publicidade do Brasil e apresentaremos as particularidades da constituição da imagem publicitária, que, muitas vezes, vai se basear em seus próprios iconogramas para se constituir. Nos valeremos das contribuições de autores como Jacques Durand, Georges Péninou e Umberto Eco, que dedicaram seu olhar a esse tipo de imagem, gerando constatações que podemos perceber, até os dias de hoje, nas produções deste tipo de imagem.

\section{Dinâmica de trabalho da publicidade no Brasil}

A publicidade impressa no Brasil, que tem seu início em 1808, com o surgimento dos primeiros jornais, é inicialmente composta apenas por textos meramente descritivos, com linguagem bastante direta. Posteriormente, diante do desenvolvimento das tecnologias de impressão é que as imagens vão sendo incorporadas: primeiramente, as ilustrações a traço e, em seguida, as fotografias, diante da possibilidade impressão por meio-tom. (RAMOS, 1985)

No Brasil, são os poetas e artistas que vão trabalhar na construção das composições publicitárias no início do século XX. Apenas a partir da década de 1950 é que temos no Brasil o surgimento do primeiro curso de formação em publicidade. Antes disso, a publicidade era estruturada por pintores, ilustradores e poetas, sendo o poeta responsável pela parte textual e pelo desenvolvimento do conceito, e os pintores e ilustradores pelas imagens que iriam acompanhar aquele texto. Neste modo de trabalho, aquele que iria elaborar a imagem o fazia tendo 
como base o pedido daquele que estruturou o texto, não havendo liberdade de criação e nem a possibilidade de sugestões de outras imagens que poderiam figurar no anúncio.

Essa dinâmica prevaleceu até a década de 1960, quando foi implantado o sistema de duplas de criação, em que redator e o diretor de arte - que é responsável pela aparência visual da composição - trabalham juntos, podendo, inclusive, dar sugestões no trabalho um do outro. Esse sistema de trabalho prevalece até os dias de hoje.

A direção de arte envolve o processo de organização e direção dos elementos visuais de qualquer meio de comunicação, compreendendo o desenho da aparência de um anúncio. Os elementos visuais que constituem o anúncio têm que funcionar juntos, de forma que maximizem o impacto da mensagem publicitária. (MAHON, 2010) Devemos lembrar que, neste tipo de mensagem, a fotografia irá se relacionar com outros elementos visuais, como grafismos, desenhos, ilustrações, pinturas, tipografia, entre outras.

Deste modo, desde a sua raiz, no início do século XX, com a implantação das primeiras agências de publicidade no Brasil, até os dias atuais, percebemos que a utilização de imagens, seja ela ilustração ou fotografia, tem o caráter de encomenda: imagens que devem se adequar a um discurso e devem se enquadrar também em uma determinada aplicação, de acordo com a mensagem planejada.

O caráter de encomenda é extremamente pautado pela dinâmica de trabalho: a dupla de criação que elabora um conceito e o diretor de arte que irá planejar que imagens precisará num dado projeto e que atmosferas elas devem ter. A etapa final envolve a contratação dos profissionais terceirizados para execução das imagens planejadas, sejam eles fotógrafos, ilustradores, pintores, entre outros.

Devemos pontuar aqui que não consideramos o processo de criação publicitária como um processo artístico. Acreditamos que pode haver algum grau de artisticidade em determinados projetos, mas, sobretudo, que é a partir de um repertório de conhecimento iconográfico da história da arte e da própria história da propaganda que a figura do diretor de arte irá ampliar as suas possibilidades criativas. Ou seja, que é possível haver influências claras de movimentos artísticos ou da poética de determinado artista na construção da imagem publicitária.

\section{A fotografia publicitária e os gêneros incorporados}

Acreditamos que a execução de uma fotografia para utilização pela publicidade envolve uma técnica, mas também um objetivo. Trata-se de uma imagem que é completamente planejada e construída e que vai contribuir para a construção da imagem de marca do cliente anunciante. No entanto, até que a linguagem publicitária se desenvolvesse e chegasse à atual configuração como nós a conhe- 
cemos e identificamos como sendo uma imagem publicitária, percorreu-se um longo caminho.

É importante pontuar que, do mesmo modo que não havia ainda a figura do publicitário e as peças publicitárias eram elaboradas por artistas, a figura do fotógrafo publicitário também não existia. Desse modo, o uso da fotografia teve como base o tipo de produção já existente com essa linguagem. O primeiro gênero a ser incorporado pela publicidade é o retrato. A fotografia, devido ao seu custo relativamente baixo, tratou de popularizar o retrato, tornando-o acessível a famílias que nunca haviam procurado um pintor para tal feito.

Conforme Éguizabal (2001), o retrato é o primeiro gênero incorporado pela publicidade, através da sua utilização em anúncios testemunhais, em que o retratado endossa a utilização de determinado produto e até mesmo dá o seu depoimento do uso e resultados obtidos. Como no caso de anúncio veiculado, na década de 1950, na revista O cruzeiro, do Sabonete Lever, em que um retrato da atriz Ruth Roman é vinculado ao uso do produto. A atriz aparece de maneira imponente segurando o produto em uma das mãos e ocupando a maior parte da composição. Ela utiliza vestes de modo que a sua pele apareça na imagem, evocando a sensação de maciez e de aparência saudável. O elemento textual, que vem entre aspas, traz uma frase testemunho da atriz em relação ao uso do produto em questão. Nestes casos, a utilização do retrato se dá pela identificação dos traços particulares da figura humana em questão. A vinculação de sua imagem ao produto ocorre pela sua particularidade e pela identificação da atividade que desenvolve: é atriz. Tal imagem irá enfatizar a ideia central da mensagem: a de que o produto é "usado por 9 entre 10 estrelas de Hollywood".

Do ponto de vista da interpretação, é essencial pensar no contexto histórico em que o anúncio foi veiculado: àquela época, tal atriz estava em evidência, sendo facilmente identificada pelo grande público como sendo uma "estrela de Hollywood". Tal utilização do retrato como traço individualizante depende dessa identificação e associação por parte do leitor da imagem.

Outro modo de utilização bastante comum do retrato pela publicidade não seria pela identificação da individualidade do retratado, mas sim pela construção de uma representação da figura humana como um tipo genérico: um homem ou uma mulher que vão representar um ideal de consumo representarão, também, atributos privilegiados pela sociedade em cada momento. (ÉGUIZABAL, 2001)

Um exemplo seria uma fotografia realizada pelo fotógrafo brasileiro Chico Albuquerque, em que há a representação de uma família do momento de uma refeição. ${ }^{1}$ Num ambiente de uma casa, há uma mesa posta em que duas crianças e um homem parecem esperar o momento da refeição. Uma mulher de pé faz

1 Disponível em: <http://tinyurl.com/lyzu718>. Acesso em: ago. 2014. 
um gesto com uma das mãos enquanto segura um prato com a outra mão. Nesta composição, podemos inferir que se trata de uma relação familiar, mas que as pessoas aqui não são retratadas por suas particularidades. As figuras humanas, aqui, representam "o pai”, “a mãe”, “os filhos”, “o marido”, “a esposa”. São retratados muito mais os papéis sociais e a estrutura familiar comum a muitos dos que iriam ser interpelados por esta imagem enquanto apelo de comunicação. Neste tipo de retrato, se preza pela identificação ou aspiração a determinado grupo ou estrutura social. A publicidade se baseia numa dada realidade social, mas apresenta imagens que também irão servir de espelho para o público, fazendo-o desejar alcançar aquele ideal de representação.

Conforme Éguizabal (2001), o retrato na publicidade não pretende a sobrevivência do retratado, mas sim a sobrevivência da marca anunciante. Ele se apresenta, então, não como um retrato, mas sim como um simulacro de retrato. Assim, a direção do olhar, a vestimenta, a hierarquia entre personagens, tudo é extremamente planejado, visto que é um tipo de imagem que visa além da construção de uma representação, a rentabilidade.

Outro gênero que a publicidade incorpora é o da natureza morta, seja sob influência do cromatismo e iluminação da pintura tradicional ou mesmo através da manipulação da imagem, no sentido de se obter efeitos como a manipulação da escala ou a sensação de movimento. Enquanto a pintura de natureza morta é envolta de simbolizações, a fotografia publicitária deste gênero tem simbolização muito baixa e nível de compreensão muito alto. (ÉGUIZABAL, 2001)

Como a publicidade e seu discurso tratam sobre os objetos de consumo, eles usualmente aparecem nas fotografias de maneira isolada, como se fosse único e melhor. É uma categoria que trata dos objetos, ainda que em pequenas composições, como alimentos, utensílios de cozinha, entre outros. Podemos exemplificar tal categoria com outra fotografia de Chico Albuquerque: um carro, ${ }^{2}$ que ocupa a maior parte da composição, é colocado junto a um fundo que, por meio de grafismos, exalta o produto. É um tipo de imagem que é enfática, afirmativa.

Outra estratégia nesse tipo de fotografia é a associação do produto a uma dada atmosfera, em que o produto em questão é representado junto a algum contexto ou ação, como em uma fotografia de autoria de Albuquerque em que o cigarro é associado à prática de esportes. ${ }^{3}$ Tal composição se dá somente devido ao período histórico em que foi criada: até então não havia regulamentação no que diz respeito à propaganda de cigarros. Sendo assim, esse produto aparece como associado à imagem daquilo que é saudável, sexy, glamoroso, divertido, entre outros.

2 Disponível em: <http://tinyurl.com/mkrh8gs>. Acesso em: ago. 2014.

3 Disponível em: < http://tinyurl.com/k9ogbsu>. Acesso em: ago. 2014. 
Pontuamos aqui que utilizamos como exemplificações, imagens de Chico Albuquerque, pois este foi um dos primeiros fotógrafos brasileiros a produzir fotografias para publicidade. Como já relatamos, não havia profissionais especializados para a produção deste tipo de imagem no país. Ele foi um dos pioneiros a aceitar a forma de trabalho que a área pedia e também a inserir os produtos numa determinada cena a ser fotografada, fazendo com que a publicidade saísse das fotografias genéricas que se somavam à ilustração do produto.

Acreditamos ainda que a incorporação dos gêneros aqui abordados será de extrema relevância para o campo da imagem publicitária, pois fornece uma estrutura formal já bastante experimentada e estudada por diversos artistas. Tal procedimento permite que a publicidade vá, aos poucos, construindo os seus próprios códigos ao longo da história. No entanto, acreditamos que ela o faz, muitas vezes, se baseando em outras imagens, como as referências da história da arte.

\section{A construção da imagem publicitária, seus iconogramas e 0 remetimento à história da arte}

Sabemos que a palavra "imagem" pode ter várias concepções e sentidos abrangentes. Joly (1996, p. 13), ao refletir sobre a palavra imagem, nos apresenta a seguinte concepção: "compreendemos que indica algo que, embora nem sempre remeta ao visível, toma alguns traços emprestados do visual e, de qualquer modo, depende da produção de um sujeito: imaginária ou concreta, a imagem passa por alguém que a produz ou reconhece". Sendo assim, podemos fazer uma imagem mental sobre algo ou alguém. Podemos produzir imagens sob suportes diversos, mas o que nos interessa aqui é pensar que a produção de imagens dependerá de um sujeito que vai produzi-la ou reconhecê-la. Este processo é essencial ao refletirmos sobre a imagem publicitária. Por se tratar de uma imagem aplicada, que tem um objetivo (de venda, de transmissão de atributos de uma marca, um conceito), o processo de reconhecimento por parte do leitor é fundamental. De que forma construir uma imagem que deve trazer uma mensagem clara de modo que o outro a compreenda? Talvez por esse motivo a publicidade usualmente trabalhe com os exageros e com seus artifícios.

Alguns autores ligados à análise da imagem já dedicaram o seu olhar a este tipo de imagem. Jacques Durand (1974, p. 20) realizou um inventário de anúncios publicitários, nos quais identificou as figuras clássicas de retórica: "Ficou claro que a maior parte das ideias criativas que estão na base dos melhores anúncios pode ser interpretada como a transposição (consciente ou não) das figuras clássicas".

Para Durand (1974, p. 20), dois níveis de linguagem são colocados em jogo por meio da retórica: o sentido próprio e o sentido figurado. "O que é dito de maneira 'figurada'poderia ser dito de maneira direta, mais simples, mais neutra". 
Um exemplo que podemos buscar na história da publicidade seriam as fotografias de pessoas doentes para a venda do remédio que curava o que os acometia. Este tipo de apelo muda quando, no anúncio de remédio, é vinculada a imagem de uma pessoa saudável. A lógica do "se você tem essa doença, use este remédio" é substituída por "se você quer ser saudável e tem determinada doença, use este remédio".

É a partir da retórica da imagem que possibilitam-se construções visuais como a metáfora, a elipse, entre outras: "A imagem retorizada, em sua leitura imediata, se liga ao fantástico, ao sonho, às alucinações: a metáfora se torna metamorfose, a repetição desdobramento, a hipérbole gigantismo, a elipse levitação, etc." (DURAND, 1974, p. 22) Por meio destes procedimentos, pode-se construir imagens mais sofisticadas, do ponto de vista do seu discurso e, como consequência, pode-se estabelecer uma comunicação mais efetiva com o leitor daquela imagem.

Dentre as operações retóricas elencadas por Durand (1974), estão: a adjunção, que se dá pela junção de um ou mais elementos à proposição; a supressão, que ocorre pela retirada de um ou mais elementos da proposição; a substituição, efetuada pela supressão seguida de adjunção: há a retirada de um elemento e sua substituição por outro; e a troca, que se dá por meio de duas substituições: há a permuta de dois elementos da proposição.

Dentre as figuras de adjunção, podemos exemplificar a abordagem pela similaridade, seja ela da forma do produto em relação a alguma outra coisa ou do conteúdo do produto. A adjunção pode acontecer, também, pela repetição de uma mesma imagem ou pela acumulação, quando se juntam elementos diferentes, remetendo à desordem. Pelo fato da publicidade tender ao exagero, ao aumento, a figura de adjunção é bastante recorrente.

No que diz respeito às figuras de supressão, é necessário que, por meio da imagem, se leve o leitor a perceber o que está ausente. A elipse seria um modo de construção por meio da supressão. No entanto, a incompletude na imagem deve ter bastante clareza, tendo em vista que o leitor não dedicará muito tempo para desvendar este tipo de imagem.

Já nas figuras de substituição pode haver a substituição idêntica, que é quando se substitui um elemento por outro idêntico; a substituição de um elemento similar, quando procura-se por elementos que formalmente se pareçam ou também pela comparação de conteúdo, como, por exemplo, se para vender um suco de frutas e comunicar que ele é 100\% extraído de frutas naturais, utilizo um copo cheio de frutas e não de suco. Pode haver, ainda, a substituição de um elemento diferente, substituindo a causa pelo efeito, como, por exemplo, a imagem de um refrigerador substituída por um bloco de gelo. (DURAND, 1974) Por meio das figuras de troca, é possível atuar por inversão ou mesmo pela troca de "papéis", como na relação pai e filho ou marido e mulher. 
Acreditamos que pode haver, numa mesma imagem, a utilização de mais de uma das figuras acima apresentadas. Como no caso de um anúncio da Kibon, ${ }^{4} \mathrm{em}$ que há a adjunção, por meio da repetição do formato do picolé nas duas páginas, e também há a supressão, na imagem do lado esquerdo, em que aparece um morango com uma parte ausente, que facilmente identificamos como sendo a forma de um picolé. Há ainda a figura de substituição, por apresentar o picolé como um substituto da fruta original, subentendendo que o produto é igualmente natural, saudável, saboroso, dentre outros benefícios que associamos à fruta natural.

Já Umberto Eco (1997), ao refletir sobre a imagem publicitária em sua relação com a iconografia, argumenta que esta se dividirá em duas estruturas: a primeira delas seria a iconografia clássica, para a qual o publicitário, muitas vezes, irá se remeter ao criar suas imagens; enquanto a segunda seria aquilo que ele denomina de "iconogramas", que são construídos no decorrer da história da publicidade e envolvem os tipos de enquadramento, de poses dos modelos fotografados, de suas hierarquias na composição, de iluminação, de ângulos para determinados produtos.

Eco diverge do pensamento de Durand, no sentido em que pensa que, justamente pela percepção estrutural deste tipo de imagem, não é mais possível ser criativo, pois tudo já foi feito. Por outro lado, Durand (1974, p. 53) acredita que a retórica pode trazer um método de criação, afirmando que "a retórica é, em suma, o repertório das diferentes maneiras pelas quais se pode ser 'original"'.

Acreditamos que a publicidade, muitas vezes, vai se remeter a outras imagens: sejam elas iconogramas, construídos no decorrer da história, ou mesmo obras de arte. Ou seja, há um olhar interior, para o seu próprio repertório, e outro que poderá se basear em pinturas, ilustrações, esculturas criadas no decorrer da história da arte. Ao se reportar a essas imagens, é possível utilizar a atmosfera criada por determinado pintor ou mesmo construir outras imagens que vão se basear na poética de determinado artista. São imagens que se baseiam em imagens.

No entanto, devemos atentar que, para utilizar a releitura na publicidade, é preciso inferir que o público irá reconhecer a imagem original que foi tomada como base para a releitura. Assim, se é uma releitura da Mona Lisa ou de A última ceia, é preciso que o público conheça previamente essas obras para que identifiquem sua influência, seja pela paleta cromática utilizada na releitura, seja pela distribuição formal dos elementos. Um exemplo seria o anúncio da BomBril ${ }^{5}$ para evidenciar o amaciante MonBijou, em que, sob o argumento de que o produto deixa a roupa uma verdadeira obra-prima, utiliza-se o garoto-propaganda da mar-

\footnotetext{
4 Disponível em: <http://tinyurl.com/nsgge63>. Acesso em: ago. 2014

5 Disponível em: <http://tinyurl.com/leuxmxj>. Acesso em: ago. 2014.
} 
ca em trajes e poses que, juntamente com o fundo e a paleta de cores, remetem à famosa obra de Leonardo da Vinci.

\section{Considerações finais}

Consideramos que a leitura de imagens é um processo particular, que envolve a bagagem cultural daquele que o faz. Sendo assim, acreditamos que é de suma importância o conhecimento de história da arte por parte daqueles que produzem imagens, sejam elas para utilização aplicada à publicidade ou não.

Pudemos perceber que a publicidade tem, no decorrer da história, seus vínculos com as artes visuais, seja por meio dos próprios artistas, que estruturavam as mensagens e imagens que compunham os anúncios, seja por meio dos gêneros que a mesma inicialmente incorporou ao utilizar a fotografia. Há também um amplo diálogo no que diz respeito à possibilidade de releituras e citações de grandes obras da história da arte.

Acreditamos que fizemos aqui uma pequena contribuição para a compreensão das relações entre a imagem publicitária e as artes visuais. Percebemos que, se por um lado ela se baseia na sua própria história e configuração, por outro, o publicitário terá que ter um grande repertório para construir as suas imagens, num movimento que o leva a se reportar não somente ao mundo que o cerca, mas também a outras imagens.

\section{Referências}

CADENA, N. V. Brasil: 100 Anos de Propaganda. São Paulo: Referência, 2001.

DURAND, J. Retórica e imagem publicitária. In: METZ, C. et al. A análise das imagens. Tradução de Luís Costa Lima e Priscila Viana de Siqueira. Petrópolis: Vozes, 1974. p. 19-59.

ECO, U. Algumas verificações: a mensagem publicitária. In: ECO, U. A estrutura ausente. São Paulo: Perspectiva, 1997. p. 157-184.

EGUIZABAL, R. Fotografia publicitária. Madrid: Cátedra, 2001.

FABRIS, A. Fotografia: usos e funções no século XIX. 2. ed. São Paulo: EDUSP, 1998.

FLUSSER, V. Filosofia da caixa preta: ensaios para uma futura filosofia da fotografia. Rio de Janeiro: Relume Dumará, 2002.

JOLY, M. Introdução à análise da imagem. Tradução de Marina Appenzeller. Campinas: Papirus, 1996.

KOSSOY, B. Fotografia \& história. São Paulo: Ateliê, 2001.

KOSSOY, B. Realidades e fiç̧̃es na trama fotográfica. 3. ed. São Paulo: Ateliê, 2002.

MAHON, N. Dirección de arte: publicidad. Barcelona: Editorial Dustavo Gili, 2010. 
PALMA, D. Do registro à sedução: os primeiros tempos da fotografia na publicidade brasileira. [S.l.], [200-]. Disponível em: <http://www.historica.arquivoestado.sp.gov.br/ materias/anteriores/edicao01/materia01/do_registro_a_seducao.pdf $>$. Acesso em: 15 jan. 2014.

PANOFSKY, E. Significado nas artes visuais. São Paulo: Perspectiva, 2004.

PÉNINOU, G. Física e metafísica da imagem publicitária. In: METZ, C. et al. A análise das imagens. Tradução de Luís Costa Lima e Priscila Viana de Siqueira. Petrópolis: Vozes, 1974. p. 60-81.

RAMOS, R. Do reclame à comunicação: pequena história da propaganda no Brasil. São Paulo: Atual, 1985. 